\title{
Metabolic activity of boar semen stored in different extenders supplemented with ostrich egg yolk lipoproteins
}

\author{
Anna Dziekońska, Marek Kinder, Leyland Fraser, \\ Jerzy Strzeżek, Władysław Kordan \\ Department of Animal Biochemistry and Biotechnology \\ University of Warmia and Mazury in Olsztyn, 10-719 Olsztyn, Poland \\ a.dziekonska@uwm.edu.pl
}

Received: December 20, 2016 Accepted: March 9, 2017

\begin{abstract}
Introduction: The aim of this study was to evaluate the effect of lipoprotein fraction isolated from ostrich egg yolk (LPFo) on the metabolic activity of boar spermatozoa following liquid semen storage in different extenders and temperatures. Material and Methods: Boar ejaculates were extended in Androhep, Beltsville thawing solution (BTS), and Martín-Rillo and Alias (MR-A) without (control) or with the addition of LPFo and stored for three days at either $5^{\circ} \mathrm{C}$ or $16^{\circ} \mathrm{C}$. The analysed sperm parameters included total motility (TMOT), plasma membrane integrity (PMI), mitochondrial membrane potential (MMP), oxygen consumption, and adenosine triphosphate (ATP) production. Results: The sperm metabolic activity seemed to be higher in the LPFo-based extenders following storage for three days, irrespective of the storage temperature. Compared with the LPFofree extenders, significantly higher $(\mathrm{P}<0.05)$ sperm PMI and MMP were observed in BTS and MR-A extenders supplemented with LPFo during storage for three days at $5^{\circ} \mathrm{C}$. Spermatozoa stored in the BTS-LPFo extender exhibited higher $(\mathrm{P}<0.05)$ TMOT and oxygen consumption, whereas higher $(\mathrm{P}<0.05)$ PMI was observed in spermatozoa stored in Androhep-LPFo and MR-A-LPFo for three days at $16^{\circ} \mathrm{C}$. No significant differences $(\mathrm{P}>0.05)$ in ATP content were observed between the LPFo-free and LPFo-based extenders during storage. Conclusions: Supplementation of LPFo to semen extenders had varying effects on the metabolic activity of boar spermatozoa stored at different temperatures. It can be suggested that the interactions of various components of the extenders and seminal plasma with LPFo exert beneficial effects on the sperm metabolic activity during liquid storage of boar semen.
\end{abstract}

Keywords: boar, sperm, extender, lipoprotein, metabolism.

\section{Introduction}

Boar semen is generally preserved in liquid state at $15-20^{\circ} \mathrm{C}$ over $1-5$ days (16). However, recent research has demonstrated that long-term extenders enhanced with proteins and antioxidants can effectively prolong the storage of semen without compromising its quality $(1,14,30)$. The viability of sperm, an important measure of fertility, can be maintained over longer periods by slowing the metabolic activity of spermatozoa (16, 19). Reduced metabolic activity decreases the rate at which sperm cells utilise substrates and accumulate metabolic by-products $(8,13)$. The metabolic rate of spermatozoa can be reduced by lowering the storage temperature. This can be achieved by preserving sperm cells with the addition of extenders that protect the sperm plasma membranes. Avian egg yolks, in particular low-density lipoproteins (LDL) isolated from hen egg yolk (HEY), offer such protective functions $(2,17,22)$. Semen extenders are enhanced with the LDL fraction from HEY to protect the sperm cells of various animal species, including boars, against osmotic and cold shock effects (3). However, the use of HEY in extenders for storage of boar semen can be controversial. Research has demonstrated that HEY contains inhibitory substances that disrupt sperm respiration and motility (24). Boar seminal plasma also contains zinc ion-dependent proteins capable of precipitating HEY components, which significantly restrict their applicability in semen storage (25). Hen egg yolk is also a potential source of microbial or viral contamination, which decreases the 
fertilising ability of spermatozoa used in insemination (24). Earlier studies have shown that the lipoprotein fraction isolated from the African ostrich's egg yolk (LPFo) can replace HEY and its components, and that it can be used in a lyophilised form for boar semen preservation $(5,9,23,26,27)$. A study conducted in our laboratory revealed that LPFo delivers unique protective effects on the sperm ultrastructure and enhances the metabolic activity and fertilising ability of sperm cells $(4,6,11,12)$. Sows were successfully inseminated with semen that was stored in the Kortowo 3 (K3) extender supplemented with LPFo at $5^{\circ} \mathrm{C}$ (refrigerator) (24).

Based on the above findings, we hypothesised that the addition of LPFo to various boar semen extenders could exert a positive effect on the metabolic efficiency of stored spermatozoa, in particular at lower temperatures. The aim of this study was to evaluate the effect of the LPFo supplementation added to Androhep, Beltsville thawing solution (BTS), and Martín-Rillo and Alias (MR-A) extenders on the metabolic efficiency of boar spermatozoa stored at $5^{\circ} \mathrm{C}$ and $16^{\circ} \mathrm{C}$. The metabolic efficiency of boar semen was evaluated based on the total motility, membrane integrity, mitochondrial membrane potential, adenosine triphosphate (ATP) content, and oxygen consumption of sperm cells.

\section{Material and Methods}

Animals and ejaculate collections. Ejaculates were collected from three Polish Large White boars, aged 1.5 to 2.5 years. A total of 12 ejaculates were obtained by the gloved-hand technique. Only semen samples with minimum $70 \%$ of total sperm motility and more than $85 \%$ of morphologically normal spermatozoa were used. Sperm morphology and acrosome integrity were assessed by the Giemsa staining method (9). Sperm concentration was assessed microscopically in a Bürker chamber (EquimedMedical Instruments, Poland). Boars were kept under standard hygienic conditions and were fed commercial pig diets.

Semen processing and preservation. The semen samples were extended $\left(30 \times 10^{6}\right.$ spermatozoa $\left./ \mathrm{mL}\right)$ in the following extenders: Androhep EnduraGuard (Minitüb, Germany), BTS (Minitüb), and MR-A (Kubus, Spain), according to the manufacturers' instructions. Semen samples were extended without the addition of LPFo (control) and with the addition of 5\% LPFo. The LPFo extraction procedure has been described elsewhere $(24,26)$. Extended semen was stored at $5^{\circ} \mathrm{C}$ (refrigerator) and $16^{\circ} \mathrm{C}$ (Thermobox, Minitüb) for three days. Besides plasma membrane integrity assessment, analyses of the parameters of the sperm metabolic activity including evaluations of total motility (TMOT), mitochondrial membrane potential (MMP), oxygen consumption, and ATP content, were conducted on the first day (day 0) and the third day of storage (day 3).

Motility evaluations. Before motility analysis, extended semen samples were held in a water bath for $10 \mathrm{~min}$ at $37^{\circ} \mathrm{C}$. For the analysis, a $5 \mu \mathrm{L}$ aliquot of sperm samples was placed on a prewarmed microscopic slide $\left(37^{\circ} \mathrm{C}\right)$, covered with a coverslip $(20 \mathrm{~mm} \times 20 \mathrm{~mm})$, and examined at $200 \times$ magnification under a light microscope (Olympus BX40, Japan) equipped with a heated stage $\left(37^{\circ} \mathrm{C}\right)$. The percentage of total motile sperm (TMOT) was assessed subjectively by visual estimation by one technician throughout the study. Sperm motility was determined by estimating the percentage of motile cells, in at least five fields, at the centre of the coverslip.

Plasma membrane integrity (PMI). Plasma membrane integrity was assessed using the dual fluorescent staining method described by Fraser et al. (10). Aliquots $(10 \mu \mathrm{L})$ of samples stained with carboxyfluorescein diacetate with propidium iodide (CFDA/PI) were examined under an epifluorescence microscope (Olympus CX41, Japan). Spermatozoa that fluoresced green over the head, midpiece, and principal piece were classified as membrane-intact, whereas spermatozoa that fluoresced red were considered to have damaged membranes. For each aliquot, approximately 200 spermatozoa were classified as cells with intact or damaged plasma membranes.

Mitochondrial membrane potential (MMP). Mitochondrial membrane potential was assessed in semen samples using dual fluorescent JC-1 probes (5,5',6,6'-tetrachloro-1,1',3,3' -tetraethylbenzimidazolylcarbocyanine iodide) (Molecular Probes, USA) with propidium iodide (PI), according to a previously described method (5). Briefly, aliquots $(10 \mu \mathrm{L})$ of stained sperm cells were examined under an epifluorescence microscope (Olympus CX41, Japan). Sperm cells displaying only orange fluorescence at the midpiece region were classified as viable spermatozoa with active mitochondria (high mitochondrial membrane potential). A minimum of 200 spermatozoa were counted per slide, using epifluorescence microscopy at $600 \times$ magnification.

ATP content. ATP content was determined with the ATP Bioluminescence Assay Kit CLSII (Roche Molecular Biochemical Company, Germany), using a Junior bioluminometer (Berthold Technologies, Germany). The ATP content of a sample was calculated from a standard ATP curve and expressed as nmol $/ 10^{8}$ spermatozoa.

Oxygen consumption. Oxygen consumption was measured polarographically using the YSI Model 5300 Biological Oxygen Monitor (Yellow Springs Instrument, USA) and Clarke's electrode, according to the manufacturer's protocol. Oxygen measurements were expressed in $\mu \mathrm{L} \mathrm{O}_{2} / 10^{8}$ spermatozoa $/ 1 \mathrm{~h} / 37^{\circ} \mathrm{C}$.

Statistical analysis. All results were expressed as means \pm standard error of the mean (SEM) and were 
analysed by repeated-measures ANOVA, using the General Linear Model (GLM) from the Statistica software package (v. 10; Statistica, USA). The main effects of extender (Androhep, Androhep-LPFo, BTS, BTS-LPFo, MR-A, and MR-A-LPFo), storage temperature $\left(5^{\circ} \mathrm{C}\right.$ or $16^{\circ} \mathrm{C}$ ), and storage time (D0 or D3) on the metabolic activity of stored spermatozoa within the storage time were analysed with a 3-way ANOVA using a $6 \times 2 \times 2$ factorial design. Significant effects were compared with the Duncan's post hoc test and were considered significant at $\mathrm{P}<0.05$.

\section{Results}

ANOVA results revealed that the extender type, storage temperature, and storage time were significant $(\mathrm{P}<0.001)$ sources of variations in all analysed parameters of sperm metabolic activity, except for ATP content. Throughout the experiments, no marked differences $(\mathrm{P}>0.05)$ in TMOT (Fig. 1A), PMI (Fig. 1B), MMP (Fig. 2A), oxygen consumption (Fig. 2B), or ATP content (Fig. 3) were observed between the LPFo-free and LPFo-based extenders on day 0 of storage.

A.
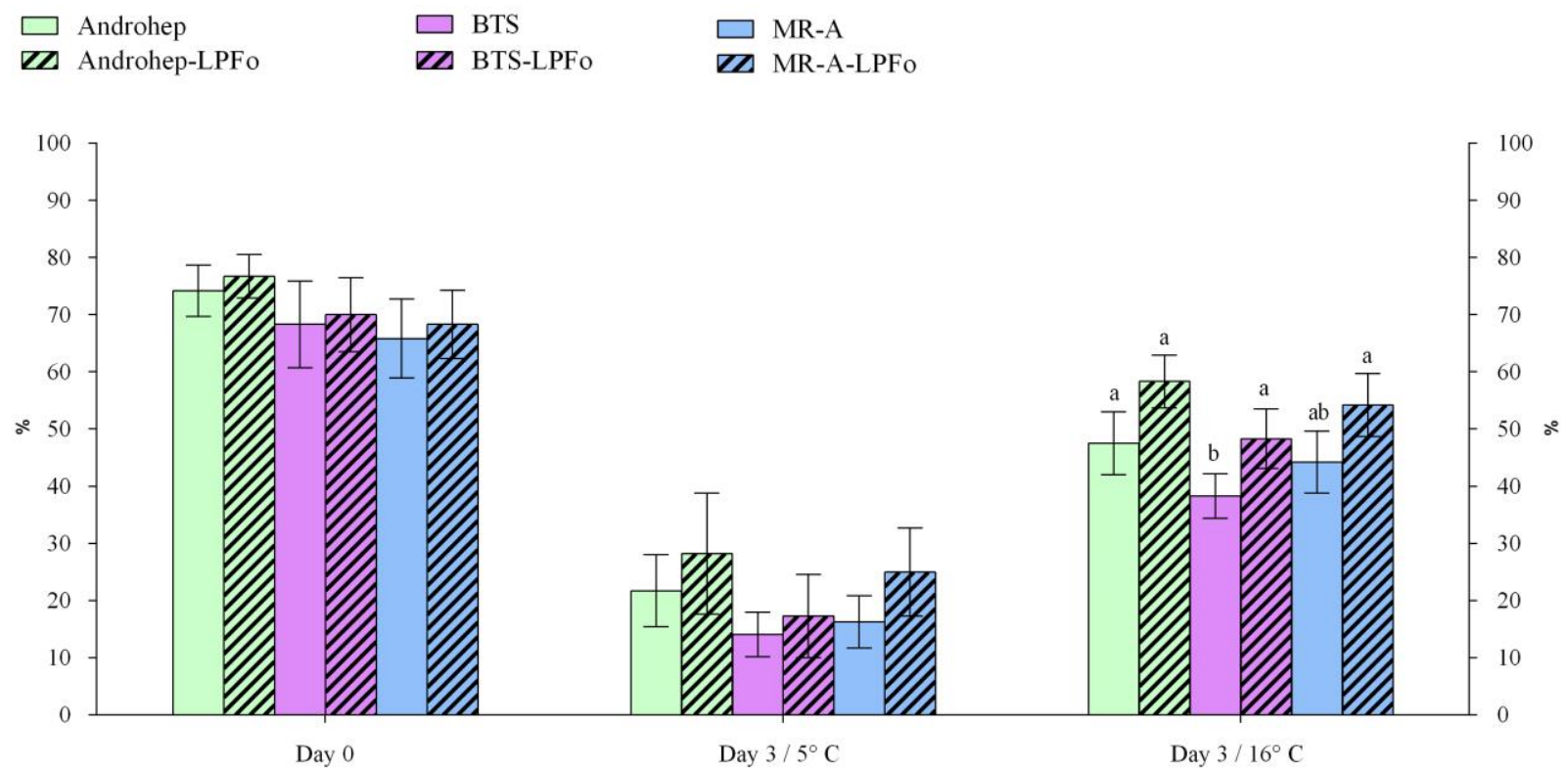

B.

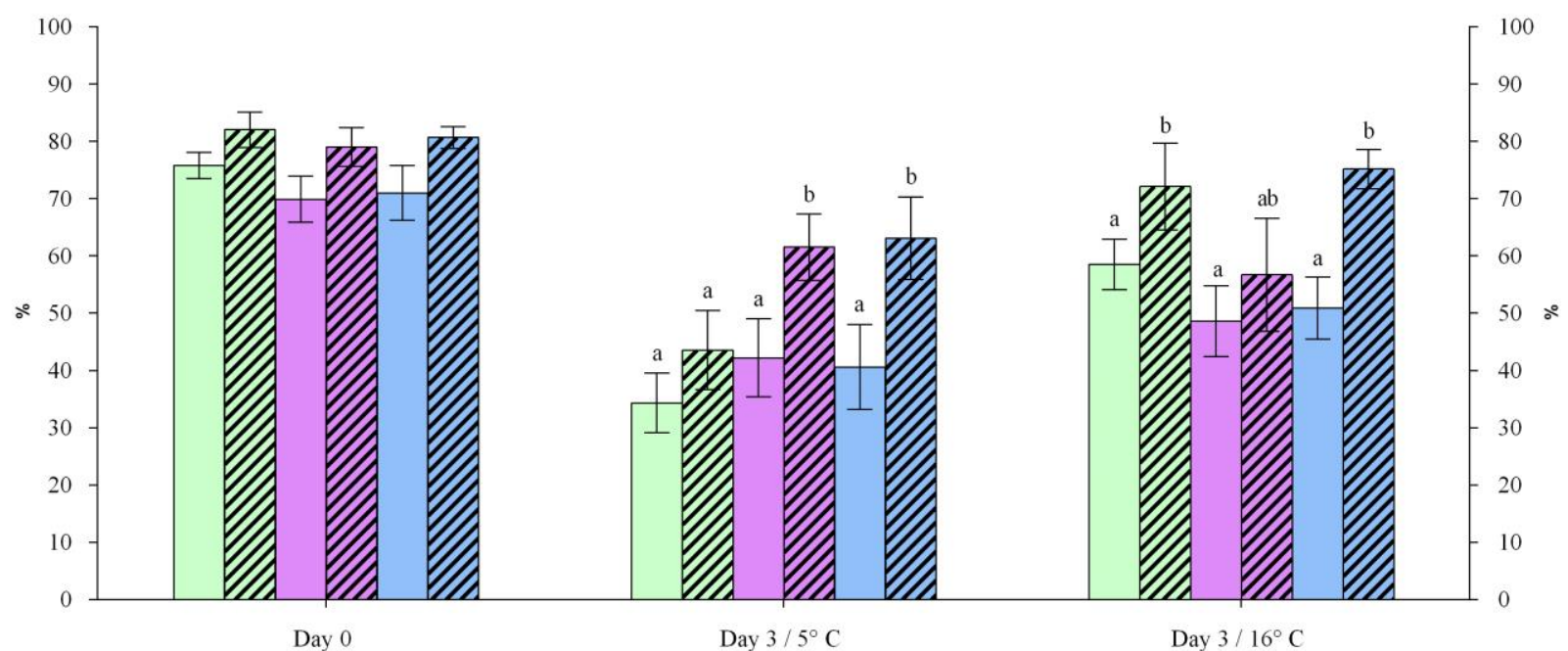

Fig. 1. The percentages of total motile spermatozoa, TMOT (A), and spermatozoa with intact PMI (B), after storage in different extenders and temperatures. Values represent the means $( \pm$ SEM) of 12 ejaculates from 3 boars. Within storage time, values with different letters (a or b) are significantly different $(\mathrm{P}<0.05)$ 
The LPFo-based extenders showed higher sperm TMOT during storage, particularly at $16^{\circ} \mathrm{C}$ (Fig. 1A). Significantly higher $(\mathrm{P}<0.05)$ percentages of motile spermatozoa were observed in the BTS-LPFo extender during storage for three days at $16^{\circ} \mathrm{C}$ (Fig. 1A). Irrespective of the extender type, TMOT was suppressed in spermatozoa stored for three days at $5^{\circ} \mathrm{C}$ compared with those stored at $16^{\circ} \mathrm{C}$ (Fig. 1A). No marked differences $(\mathrm{P}>0.05)$ in sperm TMOT were observed between the LPFo-free and LPFo-based extenders on day 3 of storage at $5^{\circ} \mathrm{C}$ (Fig. 1A). It was found that the proportions of membrane-intact (PMI) spermatozoa were significantly higher $(\mathrm{P}<0.05)$ in the MR-A extender supplemented with LPFo at both temperatures on day 3 (Fig. 1B). Furthermore, spermatozoa stored in the BTS-LPFo and AndrohepLPFo extenders exhibited significantly higher $(\mathrm{P}<0.05)$ PMI during storage for three days at $5^{\circ} \mathrm{C}$ and $16^{\circ} \mathrm{C}$ respectively (Fig. 1B).

Significantly higher $(\mathrm{P}<0.05)$ sperm MMP (Fig. 2A) and oxygen consumption (Fig. 2B) were detected in the BTS-LPFo extender during storage for three days at $5^{\circ} \mathrm{C}$ and $16^{\circ} \mathrm{C}$, respectively. Spermatozoa stored in the MR-A extender supplemented with LPFo exhibited markedly higher $(\mathrm{P}<0.05)$ MMP during storage at $5^{\circ} \mathrm{C}$ (Fig. 2A). No significant differences $(\mathrm{P}>0.05)$ in sperm MMP or oxygen consumption were observed between the LPFo-free and LPFobased extenders during storage at $16^{\circ} \mathrm{C}$ and $5^{\circ} \mathrm{C}$, respectively.

A.
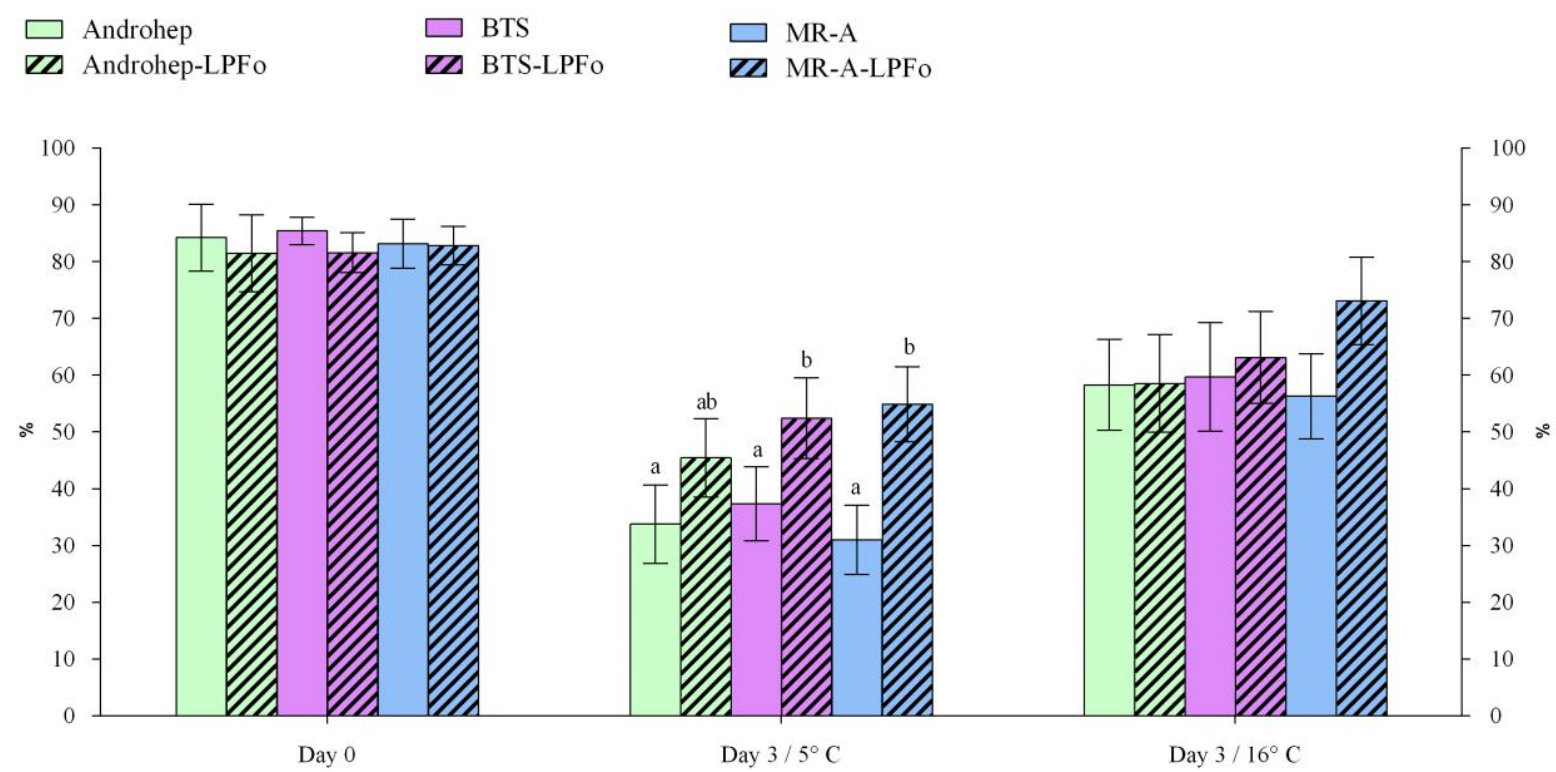

B.

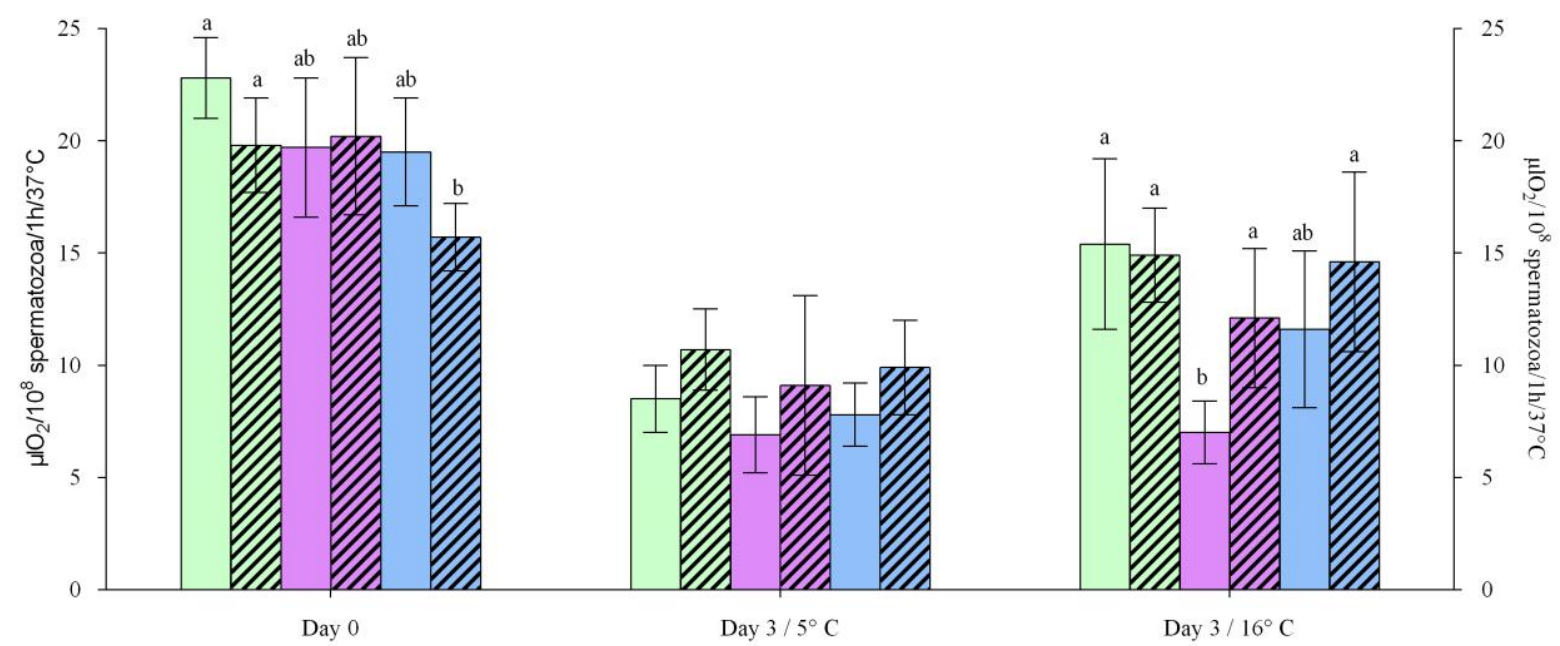

Fig. 2. The percentage of spermatozoa with high MMP (A) and oxygen consumption of spermatozoa (B) stored in different extenders and temperatures. Values represent the means $( \pm$ SEM) of 12 ejaculates from 3 boars. Within storage time, values with different letters (a or b) are significantly different $(\mathrm{P}<0.05)$ 

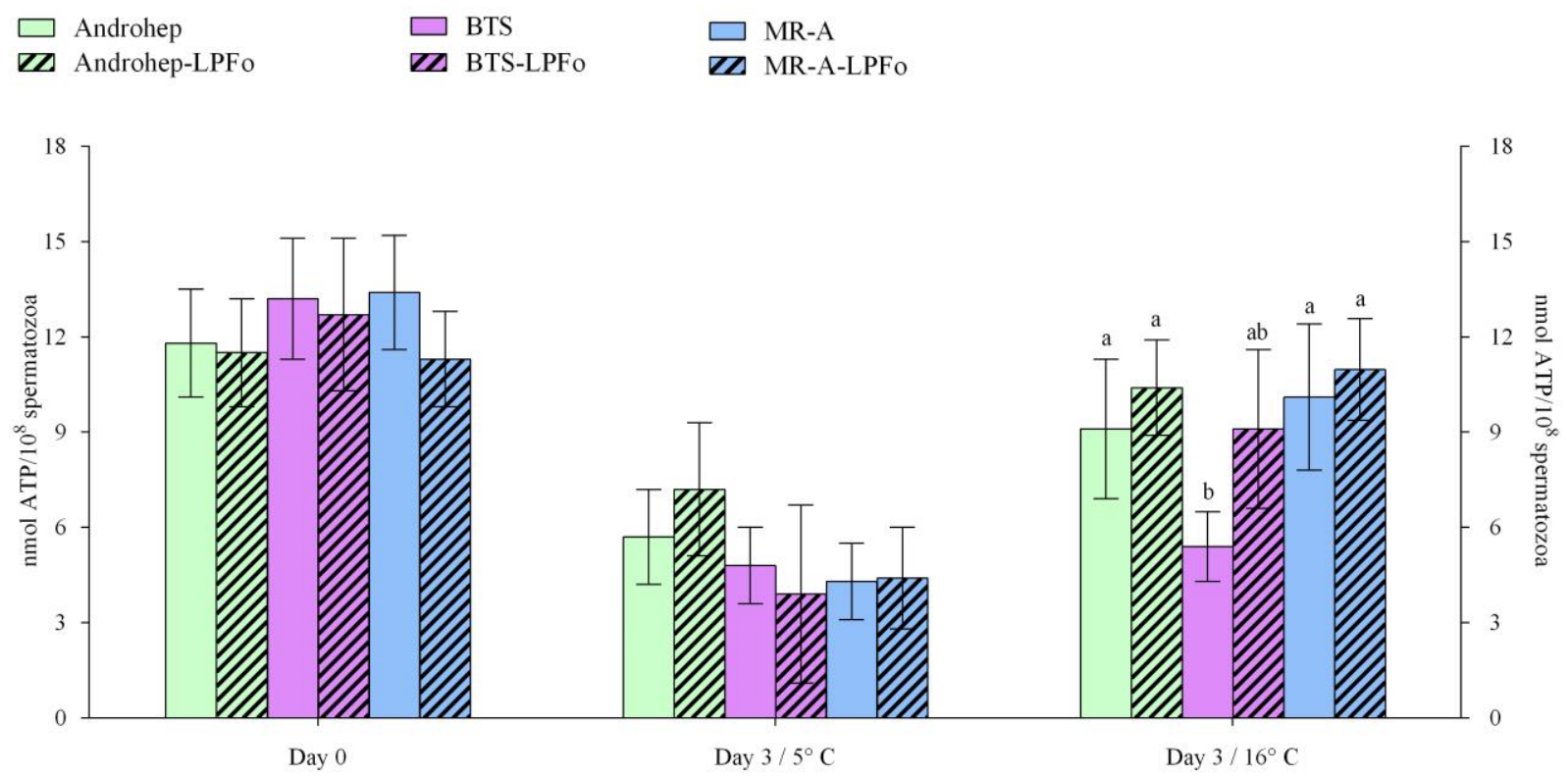

Fig. 3. ATP content of spermatozoa stored in different extenders and temperatures. Within storage time, values represent the means $( \pm$ SEM) of 12 ejaculates from 3 boars. With the storage time, values with different letters $(\mathrm{a}$ or $\mathrm{b})$ are significantly different $(\mathrm{P}<0.05)$

Even though there was a tendency towards higher ATP production in spermatozoa stored in the LPFobased extenders for three days at $16^{\circ} \mathrm{C}$, there were no significant $(\mathrm{P}>0.05)$ differences when compared with the LPFo-free extenders (Fig. 3). Also, no significant $(\mathrm{P}>0.05)$ differences in sperm ATP content were observed between the LPFo-free and LPFo-based extenders during storage at $5^{\circ} \mathrm{C}$ (Fig. 3).

\section{Discussion}

In the present study, the addition of LPFo to the semen extenders improved most of the analysed parameters of the sperm metabolic activity during storage at either $5^{\circ} \mathrm{C}$ or $16^{\circ} \mathrm{C}$. The observed effects could be attributed to the biochemical properties of LPFo. The analysed extender supplement has a unique chemical composition with a predominance of lipoproteins $(24,26)$. LPFo contains compounds that can enhance the metabolic efficiency of sperm cells, such as phosphatidylserine which protects spermatozoa against cold shock and facilitates cryopreservation (9, $11,12,26)$. Boar semen is particularly susceptible to cold shock at a temperature range of $2-12^{\circ} \mathrm{C}(28,29)$. Sperm cell plasma membranes are at the highest risk of damage caused by cold shock and oxidative stress, and changes in their molecular composition can impair the metabolic activity and fertilising ability of spermatozoa $(12,29)$. It has been demonstrated that LPFo interacts with the sperm cell plasma membranes and protects them against cold shock (12). Studies have shown that LPFo has antioxidant properties, and the LPFo-seminal plasma protein complex could inhibit lipid peroxidation during storage at $5^{\circ} \mathrm{C}(24,26)$, which could have a beneficial effect on sperm metabolic activity. In our study, the addition of LPFo to Androhep, BTS, and MR-A extenders improved the sperm PMI and MMP during storage at both $5^{\circ} \mathrm{C}$ and $16^{\circ} \mathrm{C}$. The results of this study confirmed our previous findings, which demonstrated that LPFo exerts a positive effect on the structural and functional integrity of the plasma membrane of spermatozoa during liquid storage $(5,6$, 12) or cryopreservation $(9,11)$ of boar semen. It seems that LPFo enhances the membrane integrity and mitochondrial function of spermatozoa by binding to the membranes overlying the head and midpiece regions of the sperm cells. A similar finding was reported in a previous study, which showed that LPFo enhanced the fluorescence of a membrane probe, 1-anilinonaphthalene-8-sulphonic acid (ANS), in the sperm plasma membrane overlying the head and midpiece regions, particularly at lower temperatures (12). The observed changes in PMI and MMP values suggest that the extent to which LPFo binds to the sperm cell structures is influenced by the extender type and storage temperature. The observed effects could also be attributed to the interactions of components of the extender and seminal plasma, and LPFo with the sperm plasma membrane. Plasma membrane domains in boar semen are characterised by different molecular dynamics and different responses to the components of the seminal plasma or preservation media, which could modulate molecular interactions between the egg yolk lipoproteins and spermatozoa $(12,22,25)$. 
Major components of the seminal plasma are binders of sperm proteins (BSPs), which are detrimental to sperm function during liquid semen storage or cryopreservation (17). The BSPs can bind to the sperm surface and induce cholesterol and phospholipid efflux from cell membranes in a time- and concentration-dependent manner, resulting in damaged spermatozoa, which are less resistant to cold-shock temperature. Thus, the dilution of the semen with extender comprising substances that interact with the BSPs is highly desirable for storage of spermatozoa. Several studies have confirmed that the low-density fraction of egg yolk minimises the harmful effect of the BSPs on the sperm membranes $(2,17,22)$. The BSPs interact with the low-density fraction, and more specifically with the LDL (17). Thus, greater ability of LDL to bind to the BSPs reduces the loss of phospholipid and cholesterol from the sperm membranes during liquid semen storage (2). Likewise, it is likely that LPFo binds to the BSPs, and protects the sperm membrane structures, which is manifested in reduced plasma membrane damage and increased viability and motility. In addition, the presence of components of the extenders such as bovine serum albumin (BSA) in Androhep and MR-A extenders (13) could influence the interaction mechanism with the sperm membranes (30). Similarly to LPFo, BSA has protective effects related to its specific interaction with the sperm plasma membrane phospholipids, protects spermatozoa against cold shock, and enhances their motility following semen processing. Moreover, the presence of LPFo and BSA in the extenders has been shown to protect the plasma membrane integrity of spermatozoa, which is important to maintain their function, including metabolic activity (12, 30). Therefore, the changes observed in the PMI and MMP during storage in the LPFo-based extenders at different temperatures might have influenced the rate of the energy metabolism in the sperm cells. It is noteworthy that glycolysis and oxidative phosphorylation are metabolic processes that generate energy for the sperm biological functions $(5,6,21)$. Mammalian spermatozoa get their energy from external (sperm environment) and internal (intracellular storage) sources $(15,18,21)$. As regard the extenders used in this study, the main energy source was glucose, which is the preferred substrate for metabolism in sperm cells (21). Also, spermatozoa can rely on energy sources other than monosaccharides, including extracellular metabolites such as lactate, pyruvate, citrate, glycerol, phospholipids or even triglycerides $(15,18,21)$. We have shown that LPFo comprises phospholipids and triacylglycerols, which could act as potential sources of energy for boar spermatozoa $(24,26)$. During storage, it is possible that these different sources of energy might improve the sperm mitochondrial function (higher MMP and oxygen consumption) in the LPFobased extenders, resulting in increased sperm motility compared to the LPFo-free extenders. However, there is limited information in the literature about the significance of the role of phospholipids and triacylglycerols as potential sources of energy for spermatozoa during liquid semen storage.

In the current study, the sperm metabolism was also influenced by the storage temperature. The metabolic activity of spermatozoa is considerably reduced when exposed to cold-shock temperature (4-6, 14, 20). A similar phenomenon was observed in this study when extended semen samples stored at $5^{\circ} \mathrm{C}$ were compared to those stored at $16^{\circ} \mathrm{C}$. During storage at $5^{\circ} \mathrm{C}$ there was a marked reduction in sperm mitochondrial activity, reflected by lower oxygen consumption and MMP and ATP production which is essential for the maintenance of motility (21). Furthermore, a reduction in oxygen consumption was accompanied by a marked decline in the rate of ATP production, however, there were no significant differences between the LPFo-free and LPFo-based extenders with respect to ATP content. It is difficult to explain this inconsistency and further studies will be needed to clarify this finding.

To conclude, supplementation of LPFo to Androhep, BTS, and MR-A extenders seemed to improve the metabolic efficiency of boar spermatozoa during storage for three days at different temperatures, particularly at $5^{\circ} \mathrm{C}$. The findings of our study have confirmed that the metabolic activity of stored spermatozoa was significantly influenced by the extender type, storage temperature, and storage time. Furthermore, marked changes in the metabolic activity of boar spermatozoa could be attributed to the interactions of various components of the semen extenders and seminal plasma with ostrich egg yolk lipoproteins during liquid semen storage.

Conflict of Interests Statement: The authors declare that there is no conflict of interest regarding the publication of the article.

Financial Disclosure Statement: This study was financed by research grant no. 0103.0206 from the University of Warmia and Mazury in Olsztyn.

Animal Rights Statement: Experiments on animals were conducted in accordance with the rules and standards laid down by the Local Ethics Committee regarding the handling and use of laboratory animals.

\section{References}

1. Becherer D., Batz J., Gugelmann R., Ulbrich S.E., Bollwein H., Janett F.: Long term storage of liquid preserved boar semen: A comparative study using 5 different commercial extenders. Reprod Domest Anim 2014, 49, 10, doi: 10.1111/rda.12292.

2. Bergeron A., Manjunath P.: New insights towards understanding the mechanisms of sperm protection by egg yolk and milk. Mol Reprod Dev 2006, 73, 1338-1344.

3. Demianowicz W., Strzeżek J.: The effect of lipoprotein fraction from egg yolk on some of the biological properties of boar 
spermatozoa during storage of the semen in liquid state. Reprod Domest Anim 1996, 31, 279-280.

4. Dziekońska A., Fraser L., Kinder M., Strzeżek J.: Energy metabolism in boar spermatozoa stored in different extenders at 5 degrees C and 16 degrees C. Reprod Domest Anim 2007, 42, 90, doi: 10.1111/j.1439-0531.2007.00910.x.

5. Dziekońska A., Fraser L., Strzeżek J.: Effect of different storage temperatures on the metabolic activity of spermatozoa following liquid storage of boar semen. J Anim Feed Sci 2009, 18, 638-649.

6. Dziekońska A., Strzezek J.: Boar variability affects sperm metabolism activity in liquid stored semen at 5 degrees C. Pol J Vet Sci 2011, 14, 21-27.

7. Dziekońska A., Fraser L., Majewska A., Lecewicz, M., Zasiadczyk Ł., Kordan W.: Effect of commercial long-term extenders on metabolic activity and membrane integrity of boar spermatozoa stored at 17 degrees C. Pol J Vet Sci 2013, 16, 517-525.

8. Flowers W.L.: Semen quality assurance. $49^{\text {th }}$ Ann. North Carolina Pork Con., Greenville, USA. https://www.ncsu.edu/ project/swine_extension/ncporkconf/2005/sessions/flowers.htm.

9. Fraser L., Dziekońska A., Strzeżek R., Strzeżek J.: Dialysis of boar semen prior to freezing-thawing: Its effects on post-thaw sperm characteristics. Theriogenology 2007, 67, 994-1003.

10. Fraser L., Gorszczaruk K., Strzeżek J.: Relationship between motility and membrane integrity of boar spermatozoa in media varying in osmolality. Reprod Domest Anim 2001, 36, 325-329.

11. Fraser L., Strzeżek R., Strzeżek J.: Fertilizing capacity of boar semen frozen in an extender supplemented with ostrich egg yolk lipoprotein fractions - a preliminary study. Pol J Vet Sci 2007, 10, 131-135

12. Fraser L., Zasiadczyk Ł., Strzeżek J.: Interactions of egg yolk lipoprotein fraction with boar spermatozoa assessed with a fluorescent membrane probe. Folia Histochem Cytochem 2010, 48, 292-298.

13. Gadea J.: Semen extenders used in the artificial insemination of swine. Spanish J Agric Res 2003, 1, 17-27.

14. Gączarzewicz D., Udała J., Piasecka M., Błaszczyk B., Stankiewicz T.: Storage temperature of boar semen and its relationship to changes in sperm plasma membrane integrity, mitochondrial membrane potential, and oxidoreductive capability. Turk J Biol 2015, 39, 582-594.

15. Jones A.R., Bubb W.A.: Substrates for endogenous metabolism by mature boar spermatozoa. J Reprod Fertil 2000, 119, 129-135.

16. Johnson L.A., Weitze K.F., Fiser P., Maxwell W.M.: Storage of boar semen. Anim Reprod Sci 2000, 62, 143-172.

17. Manjunath P., Veronica N., Bergeron A., Menard M.: Major proteins of bovine seminal plasma bind to the low-density lipoprotein fraction of hen's egg yolk. Biol Reprod 2002, 67, 1250-1258.

18. Medrano A., Fernández-Novell J.M., Ramió L., Álvarez J., Goldberg E., Rivera M.M., Guinovart J.J., Rigau T., RodríguezGil J.E.: Utilization of citrate and lactate through a lactate deydrogenase and ATP-regulated pathway in boar spermatozoa. Mol Reprod Dev 2006, 73, 369-378.

19. Paulenz H., Söderquist L., Pérez-Pé R., Berg K.A.: Effect of different extenders and storage temperatures on sperm viability of liquid ram semen. Theriogenology 2002, 57, 823-836.

20. Pursel V.G., Johnson L.A., Schulman L.L.: Interaction of extender composition and incubation period on cold shock susceptibility of boar spermatozoa. J Anim Sci 1972, 35, 580-584.

21. Rodríguez-Gil J.E., Bonet S.: Current knowledge on boar sperm metabolism: Comparison with other mammalian species. Theriogenology 2016, 85, 4-11.

22. Plante G., Prud'homme B., Fan J., Lafleur M., Manjunath P.: Evolution and function of mammalian binder of sperm proteins. Cell Tissue Res 2016, 363, 105-127.

23. Strzeżek J., Fraser L., Dziekońska A., Lecewicz M.: Complexity of technology preservation of boar semen - fundamental and applicative approaches. Reprod Domest Anim 2006, 41, 325-325.

24. Strzeżek J., Fraser L., Lecewicz M., Strzeżek R., Dziekońska A.: Preparation for the preservation of animal semen, particularly boar. Patent PL217869-B1. 29 Aug 2014.

25. Strzeżek J., Hopfer E.: Zinc ion-dependent protein in boar semen. I. Egg yolk precipitating activity and some biochemical properties. Anim Reprod Sci 1987, 13, 117-131.

26. Strzeżek J., Lecewicz L., Dziekońska A., Fraser L.: A simple method of extraction of lipoprotein fractions from avian egg yolk - protective effect on cooled boar semen. Theriogenology 2005, 63, 496-497.

27. Strzeżek J., Opiłowski T., Puchalski A., Fraser L., Strzeżek R., Wiśniewska B., Wysocki P., Zasiadczyk Ł.: Pierwsze knury uzyskane po inseminacji loch nasieniem kriokonserwowanym użytkowanych w fermie zarodowej. Przegl Hod 2011, 1, 16-19.

28. Watson P.F.: The roles of lipid and protein in the protection of ram spermatozoa at $5^{\circ} \mathrm{C}$ by egg yolk lipoprotein. J Reprod Fert 1981, 62, 483-492.

29. Watson P.F., Plummer J.M.: The response of boar sperm membranes to cold shock and cooling. In: Deep freezing of boar semen, edited by Johnson L.A., Larsson K., Swedish Univ Agric Sci, Uppsala, 1985, pp. 113-127.

30. Zhang X.G., Yan G.J., Hong J.Y., Su Z.Z., Yang G.S., Li Q.W., Hu J.H.: Effects of bovine serum albumin on boar sperm quality during liquid storage at $17^{\circ} \mathrm{C}$. Reprod Domest Anim 2015, 50, 263-269. 